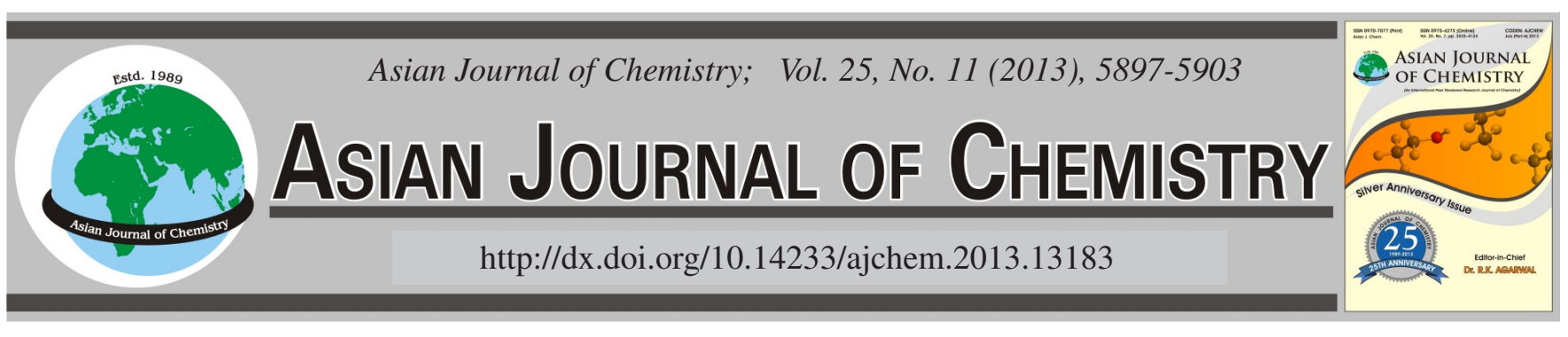

\title{
Effects of Crystal Phases and Morphology of Aluminum Oxide on the Heterogeneous Catalytic Ozonation Process Using Pyruvic Acid as an Indicator
}

\author{
S. Song ${ }^{*}$, Z. JiAng, L.Y. JiAng, Z.Q. He, M. Wu, J.J. Sun and J.M. Chen
}

College of Biological and Environmental Engineering, Zhejiang University of Technology, Hangzhou 310032, P.R. China

*Corresponding author: Tel./Fax: +86 571 88320276; E-mail: ss@ zjut.edu.cn

\begin{abstract}
Aluminum oxide as an efficient heterogeneous catalyst has received much attention in the field of ozonation. In this study, the impact of the instinct properties of $\mathrm{Al}_{2} \mathrm{O}_{3}$, including its crystalline phase and morphology, on the ozone-catalytic oxidation process were evaluated. The nanoparticles, nanotubes, nanorods, nanoleaves, nanoflakes and spindle-like 3D nanoarchitectures were constructed via hydrothermal methods and the crystal phases such as $\gamma-, \delta$-, $\theta$ - and $\alpha-\mathrm{Al}_{2} \mathrm{O}_{3}$ were controlled by appropriate calcinations using boehmite as precursor. The catalytic activity of the samples was tested by using degradation of pyruvic acid in aqueous solution in the presence of ozone, with a semicontinuous laboratory reactor. The initial degradation rates of pyruvic acid were found to correlate to the number of surface $\mathrm{OH}$ groups on the $\mathrm{Al}_{2} \mathrm{O}_{3}$. Based on these findings, along with additional information from the techniques transmission electron microscopy, $\mathrm{X}$-ray diffraction and Brunauer-Emmett-Teller measurements, it is concluded that large surface areas and the $\alpha$-phase of $\mathrm{Al}_{2} \mathrm{O}_{3}$ facilitate the degradation of pyruvic acid with ozone. The morphology effects of the catalysts were negligible in present experiments.
\end{abstract}

Key Words: Heterogeneous catalytic ozonation, $\mathrm{Al}_{2} \mathrm{O}_{3}$, Crystalline phase, Morphology, Pyruvic acid.

\section{INTRODUCTION}

Ozonation is a favoured method of water treatment due to its strong oxidizing ability, high solubility in water and leaving no harmful byproducts or sludges in the treated effluent ${ }^{1}$. In the past decades, heterogeneous catalytic ozonation, which combines catalysts with ozone for enhanced oxidation of refractory organic species, began to attract widespread attention due to having various advantages over traditional ozonation methods. These advantages include enhanced ozone utilization, increased efficiency of pollutant removal and improved organic matter mineralization ${ }^{2,3}$.

Aluminum oxide, or alumina, is a strong enough catalyst to facilitate the decomposition of organic compounds with ozone $^{4}$. For example, alumina has been reported to catalyze the ozonation of 2-chlorophenol ${ }^{5}$ and also other organic acids such as acetic acid, oxalic acid, pyruvic acid, salicylic acid and succinic acid ${ }^{6-9}$. Hence, the catalytic capacity of pure alumina for the ozonation of organic compounds could be advantageous to investigate further.

The crystal phase has been found to play an essential role in determining the catalytic performance of alumina. Alumina can exist as 8 different polymorphs $(\gamma, \delta, \rho, \eta, \theta, \kappa, \chi$ and $\alpha$ phase), each one having specific physicochemical properties.
Amongst the polymorphs, $\gamma-, \delta-, \theta-$ and $\alpha-\mathrm{Al}_{2} \mathrm{O}_{3}$ are always used in heterogeneous catalysis. The performance of various aluminum (hydroxyl) oxides, such as $\gamma$ - $\mathrm{AlOOH}, \gamma-\mathrm{Al}_{2} \mathrm{O}_{3}$ and $\alpha-\mathrm{Al}_{2} \mathrm{O}_{3}$, in decomposing aqueous ozone has been previously explored. The results show that the three aluminum oxides each exhibit a different catalytic activity, for the catalytic ozonation of 2,4,6-trichloroanisole ${ }^{10}$. However, this study did not concern the effect of specific surface area on the reaction rate. The surface area has been demonstrated to play an important role in the catalytic ozonation process ${ }^{11}$. Thus, a systematic investigation into the influence of the crystal phase of alumina on catalytic ozonation should be made on the basis of subtracting the influence of the surface area.

The catalytic activities of materials strongly depend on their morphology, and this has been demonstrated in many fields ${ }^{12-14}$. In general, nanomaterials can be categorized into zero-, one-, two- and three-dimensional (0D, 1D, 2D and 3D) nanostructures. Alumina nanoparticles (OD) are an important material when used in heterogeneous catalysis, owing to their high surface area and mesoporous properties ${ }^{15}$. Recently, the use of one-dimensional (1D) nanostructured materials, such as nanowires, nanorods, nanobelts and nanotubes, are of great interest, since their novel properties originate from their unique structural one-dimensionality and quantum size confinement 
effects in the other two dimensions ${ }^{16}$. In contrast to early studies which have focused on zero and one dimensional nanostructures, special attention has been recently paid to the synthesis of two-dimensional nanostructures ${ }^{17}$. Due to high anisotropy factors, some unique properties were observed in the twodimensional nanostructures, which suggest potential to be future high performance catalysts ${ }^{17,18}$. Moreover, the threedimensional (3D) superstructures, which are constructed using nanoscale building blocks such as nanoparticles, nanorods, nanowires and nanosheets, may have an even greater potential for catalytic applications than the 1D nanostructures. Their potential applications could include adsorption, ceramics, photonics, electrochemistry and biomedicine ${ }^{19}$. Therefore, it is predicted that the shape of $\mathrm{Al}_{2} \mathrm{O}_{3}$ will have a strong influence on the catalytic ozonation process. However, there is little knowledge about what effect morphology has on catalytic ozonation processes.

The main aim of this work is to establish the interrelation between the morphology of alumina and the initial degradation rate (IDR) of the catalytic ozonation of pyruvic acid, as well the crystal structure and the IDR, based on the quantitative determination of surface $\mathrm{OH}$ groups. Pyruvic acid was chosen as a model target pollutant in our study because it is a typical recalcitrant intermediate in the ozonation of dissolved aromatic compounds.

\section{EXPERIMENTAL}

In addition to the synthesis of nanoleaf using $\mathrm{AlCl}_{3}$ as starting material, $\mathrm{Al}\left(\mathrm{NO}_{3}\right)_{3} \cdot 9 \mathrm{H}_{2} \mathrm{O}$ was chosen as $\mathrm{Al}$ precursor for preparing the rest $\mathrm{Al}_{2} \mathrm{O}_{3}$ catalysts. $\gamma-\mathrm{Al}_{2} \mathrm{O}_{3}$ nanoparticles were synthesized using the thermal decomposition of boehmite. $\delta$-, $\theta$ - and $\alpha$-nanoparticles were prepared by appropriately calcining $\gamma-\mathrm{Al}_{2} \mathrm{O}_{3}$ nanoparticles ${ }^{16,20-23}$. Nanotubes, nanorods, nanoleaves, nanoflakes and spindle-like nano-alumina were prepared using hydrothermal processes, followed by different methods of calcinations ${ }^{16,17,24-26}$.

The nomenclature used to represent the catalysts is as follows: X-Y-Z, where X represents the abbreviation of the shape of the catalyst, including nanoparticle (NP), nanotube (NT), nanorod (NR), nanoleaf (NL), nanoflake (NF) and spindle-like nanoarchitecture (NS), Y denotes the annealing temperature $\left({ }^{\circ} \mathrm{C}\right)$ and $\mathrm{Z}$ is the crystalline phase.

General procedure: To test the different catalytic activity of the prepared $\mathrm{Al}_{2} \mathrm{O}_{3}$ catalysts in the degradation of pyruvic acid, ozonation experiments were performed in a semicontinuous system (a continuous ozone gas supply with a fixed volume of water sample) by using the apparatus shown in Fig. 1. Ozone gas was generated from pure oxygen using a CHYF-3A ozone generator (Hangzhou Rongxin Electronic Equipment Co., Ltd., China). The flow rate of the mixture of $\mathrm{O}_{2}$ and $\mathrm{O}_{3}$ was regulated by a mass flow controller (D07-12A/ ZM, Beijing Qixing Electronic Equipment Co., Ltd., China) at $300 \mathrm{~mL} / \mathrm{min}$. The mixture gas flow was produced as fine bubbles through a porous plastic diffuser located at the bottom of a flat-bottomed glass reactor, which had a total volume of $400 \mathrm{~mL}$ (height of $320 \mathrm{~mm}$ and an inner diameter of $40 \mathrm{~mm}$ ). Excess ozone leaving the reactor was trapped by gas absorption bottles containing a $2 \%(\mathrm{w} / \mathrm{v}) \mathrm{KI}$ solution. Before each

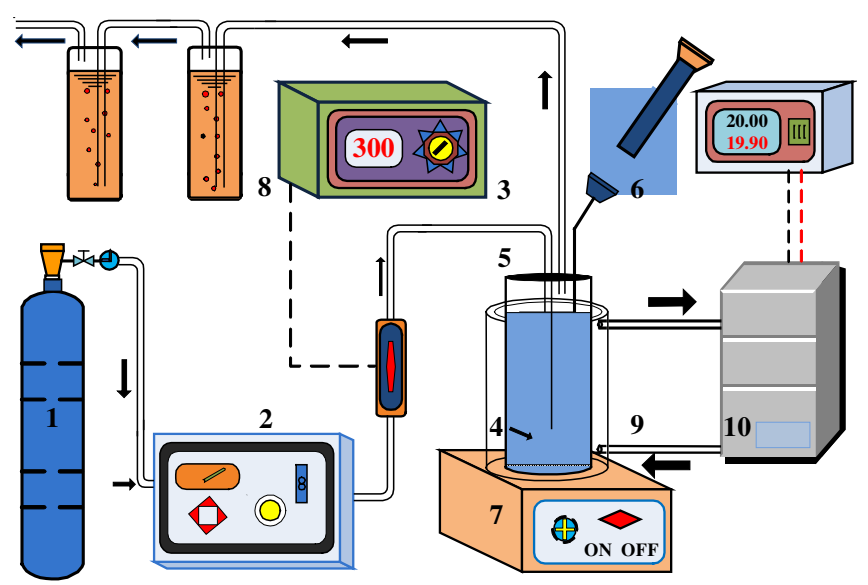

Fig. 1. Apparatus for ozonation: 1. Oxygen cylinder. 2. Ozone generator. 3. Mass flow controller. 4. Porous pellet. 5.Ozonation reactor. 6. Sampling system. 7. Magnetic stirrer. 8. KI solution. 9. Water bath vessel.10. Thermometer

run, $300 \mathrm{~mL}$ of simulated wastewater containing $0.9 \mathrm{mmol}$ pyruvic acid and $1.2 \mathrm{~g}$ of catalysts were introduced into the reactor. The reaction solution was stirred continuously using a magnetic stirring bar for good mixing. A sample of the suspension was withdrawn at preset time intervals to determine the residual chemical oxygen demand (COD). The solution temperature was controlled at $20 \pm 1^{\circ} \mathrm{C}$ by a thermostatic bath (THD-2006, Ningbo Tianheng Instrument Factory, China) and the ozone concentration of the fed-gas was determined to be $c a .55 \mathrm{mg} / \mathrm{L}$ using a known iodimetric method ${ }^{27}$. Measurement of the COD was performed according to standard methods. The same procedures were used for the control experiments of single ozonation without a catalyst.

It should be noted that pyruvic acid can be adsorbed by $\mathrm{Al}_{2} \mathrm{O}_{3}$ powders ${ }^{9,28}$. To eliminate the effect of adsorption on the evaluation of catalytic activities of $\mathrm{Al}_{2} \mathrm{O}_{3}$ upon pyruvic acid degradation, $\mathrm{COD}$ values were measured without the removal of $\mathrm{Al}_{2} \mathrm{O}_{3}$ particles. This method is acceptable since no obvious differences were observed in the COD values with and without using $\mathrm{Al}_{2} \mathrm{O}_{3}$ powders in an additional experiment.

Detection method: $X$-ray diffraction (XRD), transmission electron microscopy (TEM) and Brunauer-Emmett-Teller (BET) were adopted to characterize the samples with respect to their phase composition, morphology and phase structure. The concentration of surface $\mathrm{OH}$ groups (expressed in mmol per unit gram) was measured by a saturated deprotonation method as described ${ }^{29}$. The method is demonstrated to be accurate and the amount of the dissolved aluminum was found to be negligible.

\section{RESULTS AND DISCUSSION}

Catalyst characterization: For correlating the physicochemical properties of the catalysts with the heterogeneous catalytic degradation of pyruvic acid in the presence of ozone, the $\mathrm{Al}_{2} \mathrm{O}_{3}$ powders were characterized by the means of XRD, TEM and BET techniques.

Assisted by using the XRD technique, we characterized the crystal phases of the catalysts to determine whether a singlephase aluminum oxide had been prepared. As shown in Fig. 2 , all the reflections can be indexed to the alumina without 
any indication of crystalline byproducts and different calcination routes lead to quite different crystalline phases. The diffraction peaks of the sample nanoparticle-500- $\gamma$ can be assigned to a pure crystalline phase, with the lattice constants being in good agreement with $\gamma-\mathrm{Al}_{2} \mathrm{O}_{3}$ (indexed to JCPDS 100425). Using various temperature programs, the nanoparticle powders calcined at $900{ }^{\circ} \mathrm{C}$ could correspond to $\delta-\mathrm{Al}_{2} \mathrm{O}_{3}$ (JCPDS 04-0877) and $\theta-\mathrm{Al}_{2} \mathrm{O}_{3}$ (JCPDS 11-0517), respectively. Moreover, all detectable peaks of sample nanoparticle-1250$\alpha$ belong to $\alpha-\mathrm{Al}_{2} \mathrm{O}_{3}$ (JCPDS 10-0173).

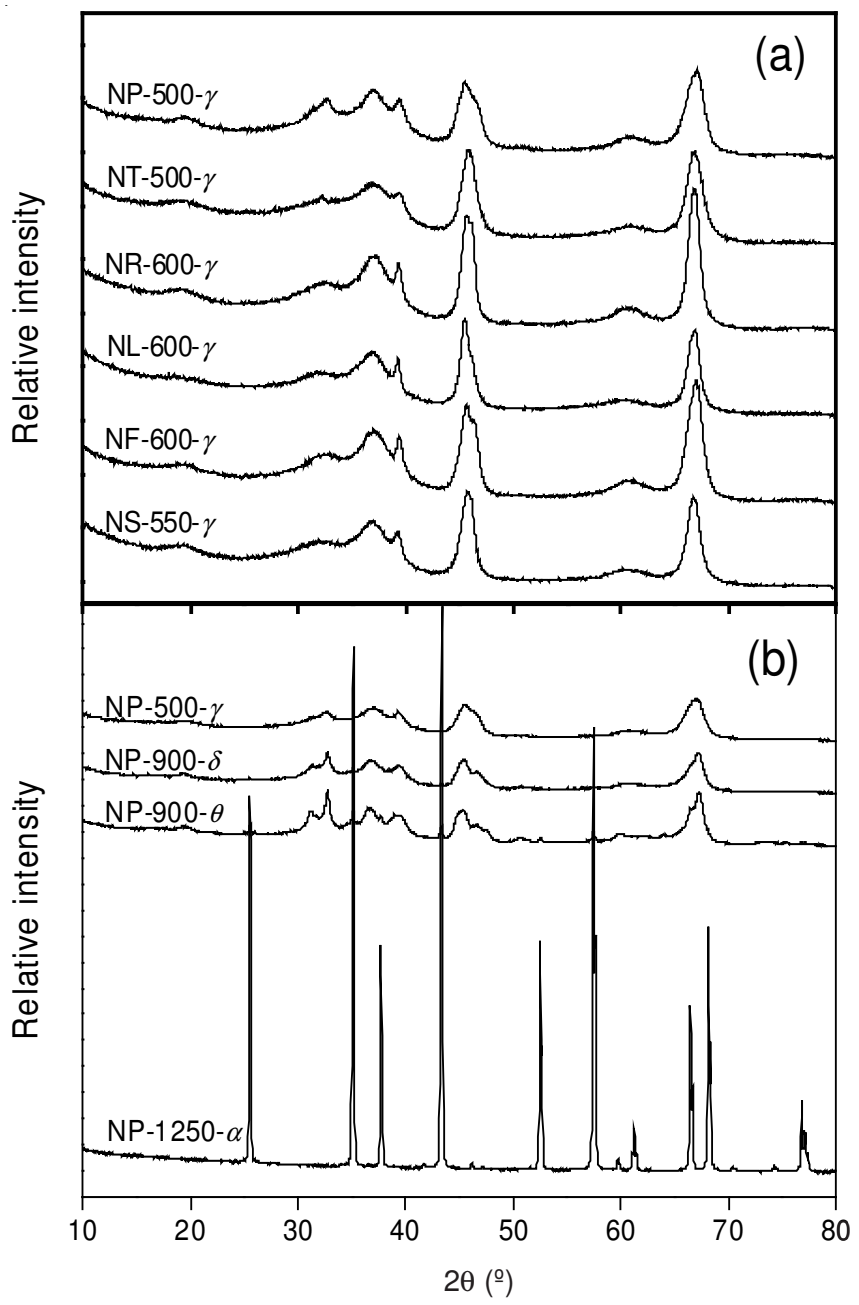

Fig. 2. XRD patterns of $\mathrm{Al}_{2} \mathrm{O}_{3}$ catalysts with various (a) morphology and (b) crystal phases
The grain size of the nanoparticle materials was roughly estimated using Scherrer's formula. Applied to the peaks of (440), (042), (240) and (113) of NP-500- $\gamma$, NP-900- $\delta$, NP$900-\theta$ and NP-1250- $\alpha$, grain sizes of $4.4,5.9,6.0$ and 177.2 $\mathrm{nm}$ were obtained, respectively. This implies the crystalline size increases with an increased annealing temperature.

In addition, NP-500- $\gamma$, NT-500- $\gamma$, NR-600- $\gamma$, NL-600- $\gamma$, NF-600- $\gamma$ and NS-550- $\gamma$ all had similar $2 \theta$ values of the diffraction peaks, exhibiting clear diffraction peaks at $19.3^{\circ}$, $31.9^{\circ}, 37.2^{\circ}, 39.4^{\circ}, 45.8^{\circ}, 60.8^{\circ}$ and $66.9^{\circ}$. These values could be assigned to the well crystallized $\gamma$-phase of (111), (220), (311), (222), (400), (511) and (440) crystal planes, respectively, when compared to standard diffraction peaks (JCPDS 10-0425). No other peak was observed belonging to the impurities. This suggests that no additional phase was contained in the samples except the $\gamma$ forms.

TEM analysis has been conducted to clearly depict the characteristics of the samples. Fig. 3 a and g-i show that with an increase in the calcination temperature from 500 to 1250 ${ }^{\circ} \mathrm{C}$, the particle diameter of the aluminum oxides increases from $c a$. 5 to $c a .130 \mathrm{~nm}$. This is roughly in accordance with the Scherrer analysis of the XRD data. The enlargement of the catalyst nanocrystals should be the consequence of the agglomeration of the phase present. Furthermore, it can be clearly seen that the morphologies are different from those of the samples prepared using different routes. As reflected in Fig. 3, the samples of NP-500- $\gamma$, NT-500- $\gamma$, NR-600- $\gamma$, NL$600-\gamma, \mathrm{NF}-600-\gamma$ and NS-550- $\gamma$ all display the clear-cut images of nanoparticle, nanotube, nanorod, nanoleaf, nanoflake and spindle-like morphology, respectively. The nanotubes have an outer diameter of $c a .5 .5 \mathrm{~nm}$ and an inner diameter of $c a$. $2 \mathrm{~nm}$. The straight nanorods have diameters ranging from 12 to $15 \mathrm{~nm}$, with lengths of about $100-300 \mathrm{~nm}$. The shapes of the plate-like nanostructures are quadrangles with sizes of 20$60 \mathrm{~nm}$ in width. The uniform leaf-like morphology shows a lateral size of approximately $4.0 \mu \mathrm{m} \times 8.5 \mu \mathrm{m}$ and the spindlelike particles are $c a$. $1.5 \mu \mathrm{m}$ in length and are composed of many oriented nanoplatelets.

The BET specific surface area $\left(\mathrm{S}_{\mathrm{BET}}\right)$ of the prepared samples is listed in Table-1. It can be observed that the $\mathrm{S}_{\mathrm{BET}}$ generally decreases with an increase in the annealing temperature. $S_{\mathrm{BET}}$ values are $231,121,137$ and $11.8 \mathrm{~m}^{2} / \mathrm{g}$ and correspond to the crystalline phases of $\gamma, \delta, \theta$ and $\alpha$, respectively. In addition, samples annealed in the temperature range of 500$600{ }^{\circ} \mathrm{C}$ show largely different specific surface areas as a function

\begin{tabular}{|c|c|c|c|c|c|c|}
\hline \multicolumn{7}{|c|}{$\begin{array}{c}\text { TABLE-1 } \\
\text { REFINED PHYSICOCHEMICAL PARAMETERS AND THE INITIAL DEGRADATION } \\
\text { RATE OF PYRUVIC ACID (PA) FOR THE PREPARED CATALYSTS }\end{array}$} \\
\hline Sample & $\begin{array}{c}\mathrm{S}_{\mathrm{BET}} \\
\left(\mathrm{m}^{2} \mathrm{~g}^{-1}\right)\end{array}$ & $\begin{array}{c}\text { Crystallite } \\
\text { phase }\end{array}$ & $\begin{array}{c}\text { Concentration of } \\
\text { surface-OH }\left(\mathrm{mmol} \mathrm{g}^{-1}\right)\end{array}$ & $\begin{array}{c}\text { Density of surface- } \\
\mathrm{OH}\left(\mu \mathrm{mol} \mathrm{m}{ }^{-2}\right)\end{array}$ & $\begin{array}{l}\text { Initial degradation rate } \\
\text { (IDR) }\left(\mathrm{mg} \mathrm{L}^{-1} \mathrm{~min}^{-1}\right)\end{array}$ & $\begin{array}{c}\text { IDR/S } \\
\left(\mathrm{mg} \mathrm{L}^{-1} \mathrm{~min}^{-1} \mathrm{~m}^{-2}\right)\end{array}$ \\
\hline NP-500- $\gamma$ & 231 & $\gamma$ & $0.247 \pm 0.014$ & $1.07 \pm 0.06$ & $8.31 \pm 1.04$ & $0.036 \pm 0.005$ \\
\hline NT-500- $\gamma$ & 214 & $\gamma$ & $0.245 \pm 0.005$ & $1.15 \pm 0.02$ & $6.18 \pm 0.87$ & $0.029 \pm 0.004$ \\
\hline NR-600- $\gamma$ & 223 & $\gamma$ & $0.211 \pm 0.010$ & $0.95 \pm 0.05$ & $7.07 \pm 0.80$ & $0.032 \pm 0.004$ \\
\hline NL-600- $\gamma$ & 58 & $\gamma$ & $0.064 \pm 0.005$ & $1.10 \pm 0.09$ & $2.32 \pm 0.58$ & $0.040 \pm 0.010$ \\
\hline$N F-600-\gamma$ & 89 & $\gamma$ & $0.096 \pm 0.001$ & $1.08 \pm 0.01$ & $3.49 \pm 0.33$ & $0.039 \pm 0.004$ \\
\hline NS-550- $\gamma$ & 205 & $\gamma$ & $0.212 \pm 0.011$ & $1.04 \pm 0.05$ & $5.34 \pm 0.44$ & $0.026 \pm 0.002$ \\
\hline NP-900- $\delta$ & 121 & $\delta$ & $0.160 \pm 0.004$ & $1.32 \pm 0.04$ & $6.11 \pm 0.24$ & $0.051 \pm 0.002$ \\
\hline NP-900- $\theta$ & 137 & $\theta$ & $0.188 \pm 0.010$ & $1.37 \pm 0.08$ & $6.74 \pm 1.77$ & $0.049 \pm 0.013$ \\
\hline NP-1250- $\alpha$ & 11.8 & $\alpha$ & $0.033 \pm 0.005$ & $2.36 \pm 0.28$ & $1.15 \pm 0.24$ & $0.106 \pm 0.020$ \\
\hline
\end{tabular}




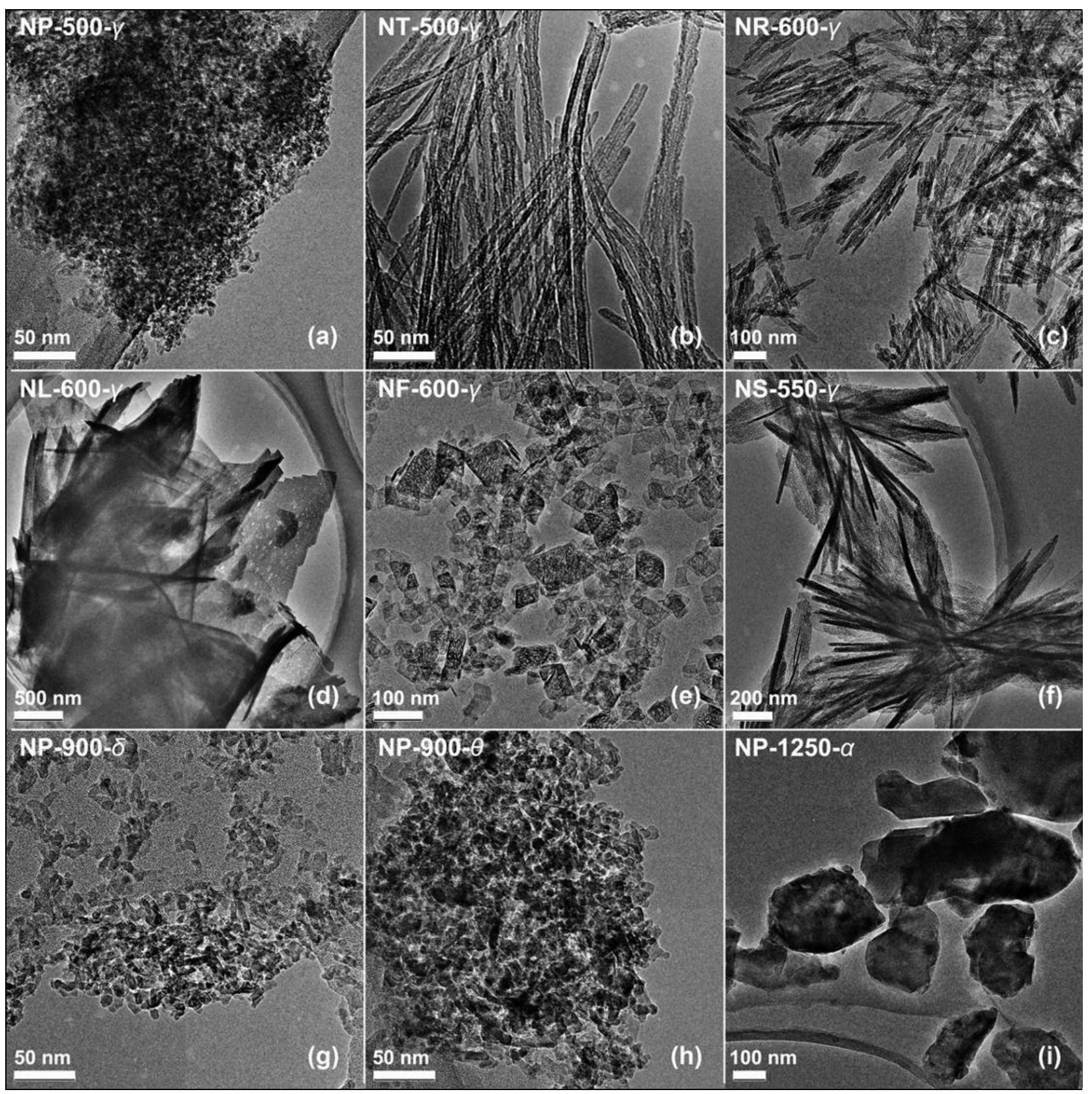

Fig. 3. TEM images of catalysts powders: (a) $\gamma-\mathrm{Al}_{2} \mathrm{O}_{3}$ nanoparticles, (b) $\gamma-\mathrm{Al}_{2} \mathrm{O}_{3}$ nanotubes, (c) $\gamma-\mathrm{Al}_{2} \mathrm{O}_{3}$ nanorods, (d) $\gamma$ - $\mathrm{Al}_{2} \mathrm{O}_{3}$ nanoleaves, (e) $\gamma-\mathrm{Al}_{2} \mathrm{O}_{3}$ nanoflakes, (f) spindle-like $\gamma-\mathrm{Al}_{2} \mathrm{O}_{3} 3 \mathrm{D}$ nanoarchitectures, (g) $\delta$ - $\mathrm{Al}_{2} \mathrm{O}_{3}$ nanoparticles, (h) $\theta-\mathrm{Al}_{2} \mathrm{O}_{3}$ nanoparticles, (i) $\alpha-\mathrm{Al}_{2} \mathrm{O}_{3}$ nanoparticles

of morphology. The largest $\mathrm{S}_{\mathrm{BET}}$ value of $231 \mathrm{~m}^{2} / \mathrm{g}$ obtained for the sample NP-500- $\gamma$, while the NL-600- $\gamma$ has the smallest BET surface area of $58 \mathrm{~m}^{2} / \mathrm{g}$.

Activity of $\mathrm{Al}_{2} \mathrm{O}_{3}$ in the catalytic ozonation: $\mathrm{A} C \mathrm{COD}$ test is an effective tool for indirectly measuring the amount of organic compounds in water. Hence, COD reduction was used as the primary target for evaluating the efficiency of the catalytic ozonation of pyruvic acid. As shown in Fig. 3, ozone alone does not cause a significant degradation of pyruvic acid after $2 \mathrm{~h}$ of treatment because there was only about a $7.5 \%$ decrease in COD with ozone alone. In comparison, catalytic ozonation with $\mathrm{Al}_{2} \mathrm{O}_{3}$ exhibited excellent performance. The difference between COD removal in the catalyzed and uncatalyzed ozonation processes indicated that the ozone itself is not a strong enough catalyst to degrade pyruvic acid and alumina can enhance the ozone oxidation process.

It is well accepted that the degradation rate would fluctuate during each experimental run. This can be explained due to the complicating effects of reaction products undergoing further reactions. Accordingly, we used the initial degradation rate to evaluate the catalytic activity of $\mathrm{Al}_{2} \mathrm{O}_{3}$. Initial degradation rate is the instantaneous rate at the beginning of a reaction. The solution $\mathrm{pH}$ was almost the same in the case for all experiments. In addition, the efficient degradation of pyruvic acid with ozone is believed to originate mostly from the surface $\mathrm{OH}$ groups on alumina, which will be discussed further. Therefore, it was not found necessary to control the $\mathrm{pH}$ of the solution in our experiments. 
As depicted in Fig. 4 and Table-1, 9 types of alumina exhibited distinct remarkable catalytic activity in catalytic ozonation for the degradation of pyruvic acid. The catalytic activities assessed by the initial degradation rate decreased in the following order: NP-500- $\gamma>$ NR-600- $\gamma>$ NP-900- $\theta>$ NT$500-\gamma>$ NP-900- $\delta>$ NS-550- $\gamma>$ NF-600- $\gamma>$ NL-600- $\gamma>$ NP$1250-\alpha$. At first inspection, the calcined temperature is shown to have a negative effect on the catalytic activity, as the pyruvic acid degradation decreases with the increasing temperature of calcination. Furthermore, activities of alumina seem to be controlled by the morphology of the catalysts. Nanoparticles calcined in air at $500{ }^{\circ} \mathrm{C}$ (i.e., NP-500- $\gamma$ ) reveal the highest pyruvic acid conversion whereas nanoparticles calcined in air at $1250{ }^{\circ} \mathrm{C}$ are the least efficient catalyst. The initial degradation rate of the former reached $8.31 \mathrm{mg} /(\mathrm{L} \mathrm{min})$, which exceeded that of the later by a factor of about 7.23-fold.

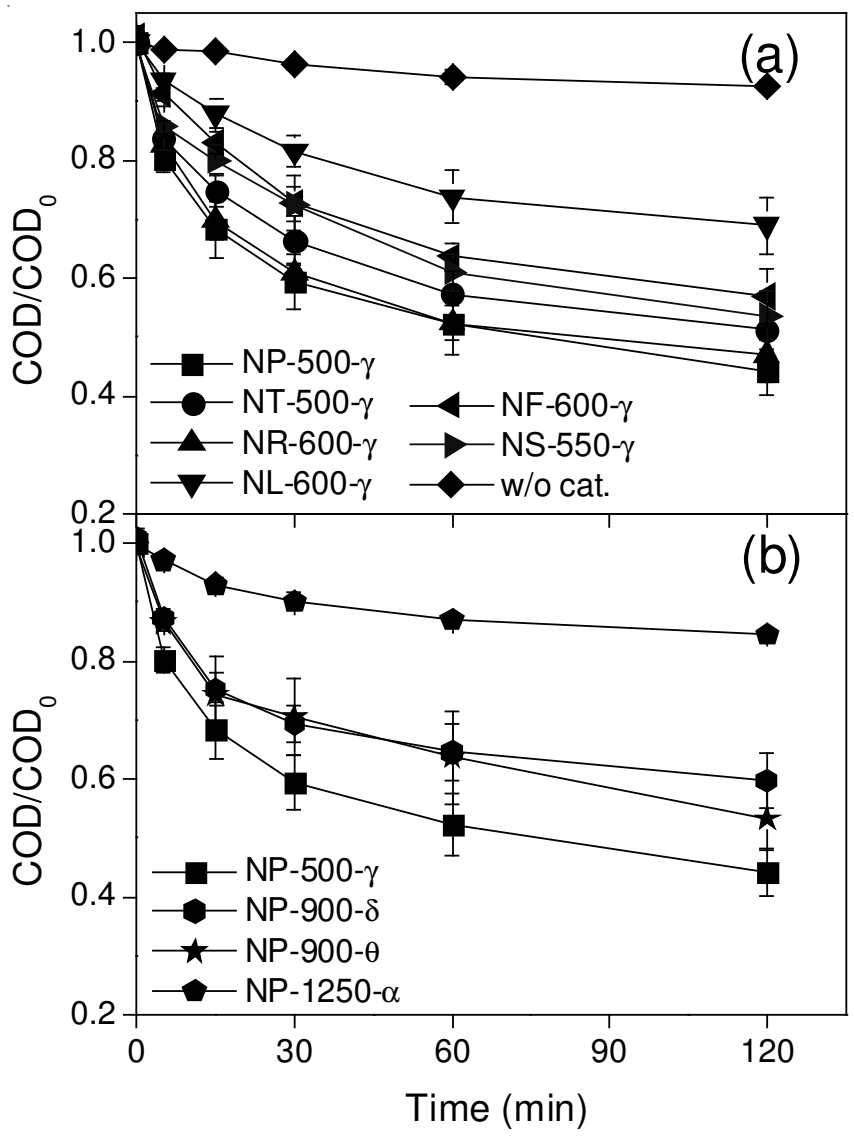

Fig. 4. COD removal during the degradation of pyruvic acid by single ozonation and by ozonation over $\mathrm{Al}_{2} \mathrm{O}_{3}$ with various morphology (a), as well as by ozonation over $\mathrm{Al}_{2} \mathrm{O}_{3}$ with various crystal phases. Experimental conditions: initial concentration of pyruvic acid, 3 $\mathrm{mmol} / \mathrm{L}$; catalyst dose, $4.0 \mathrm{~g} / \mathrm{L} ; \mathrm{O}_{3} / \mathrm{O}_{2}$ flow rate, $300 \mathrm{~mL} / \mathrm{min}$

Álvarez et al. ${ }^{9}$ reported that the removal of pyruvic acid by ozonation in the presence of $\mathrm{Al}_{2} \mathrm{O}_{3}$ occurred on the catalyst surface, where the carboxylate ions of the acids substitute the surface hydroxyl groups of alumina ${ }^{28,30}$. Thus, for investigating the effect of the crystalline phases and morphology of the catalysts on the catalytic activities of alumina, surface $\mathrm{OH}$ groups were determined accurately and the results are given in Table-1. It is clear from Fig. 5 that there is a strong linear correlation between initial degradation rate and the relative concentration of surface $\mathrm{OH}$ in the degradation of pyruvic acid with ozone. On this basis, the degradation trend can be interpreted in detail from the effects of crystal phases and morphology.

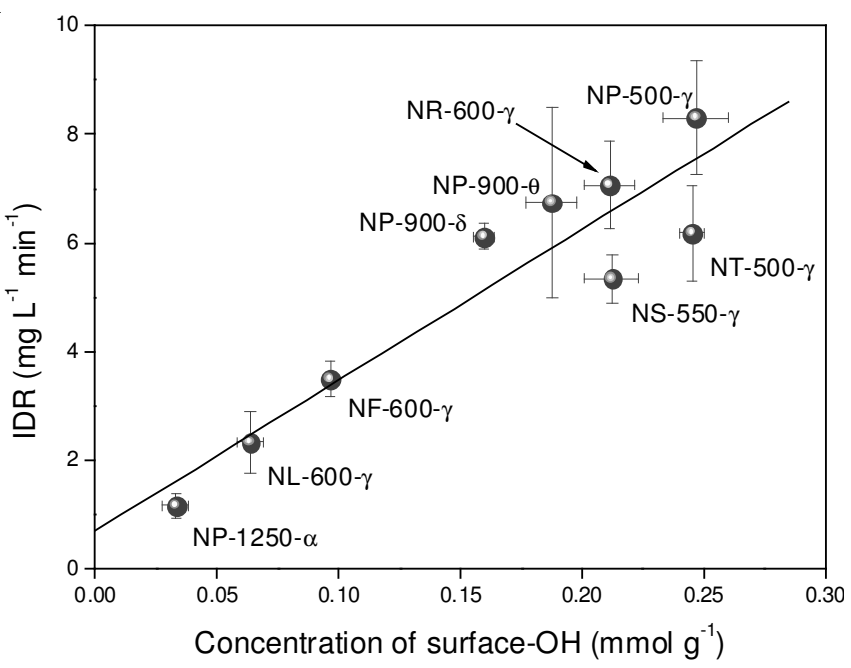

Fig. 5. Relationship between the initial degradation rate (IDR) of pyruvic acid (PA) and the concentration of surface $\mathrm{OH}$ groups on catalysts

Effect of morphology on the catalytic ozonation of pyruvic acid: The morphology of catalysts may affect the catalytic activities. In relation to the effect of morphology on the catalyzed ozonation of pyruvic acid, various shapes of $\gamma$ $\mathrm{Al}_{2} \mathrm{O}_{3}$, referred to as NP-500- $\gamma$, NT-500- $\gamma$, NR-600- $\gamma$, NL-600$\gamma, \mathrm{NF}-600-\gamma$ and NS-550- $\gamma$, respectively, have been recorded in Fig. 3a and Table-1. The examined catalyzed ozonation data exhibited varied degrees of degradation, with the initial degradation rate ranging from $c a .2 .32$ to $8.31 \mathrm{mg} /(\mathrm{L} \mathrm{min})$. Also, $\mathrm{Al}_{2} \mathrm{O}_{3}$ with a higher specific surface area displayed a faster initial degradation rate, with values of $8.31,7.07,6.18,5.34$, 3.49 and $2.32 \mathrm{mg} /(\mathrm{L}$ min $)$ when the BET area is 231,223 , 214, 205, 89 and $58 \mathrm{~m}^{2} / \mathrm{g}$, respectively. However, no obvious differences of the IDR/S could be found among different morphology of $\gamma-\mathrm{Al}_{2} \mathrm{O}_{3}$ including nanotubes, nanorods, nanoleaves, nanoflakes and spindle-like nanoarchitecture.

Similarly, Table- 1 shows a trend that the concentration of surface $\mathrm{OH}$ strongly depends on the surface area for samples with the $\gamma$ phase. The data suggest that a higher concentration of surface $\mathrm{OH}$ is featured on the higher $\mathrm{S}_{\mathrm{BET}}$ of catalyst and appears propitious to the degradation of pyruvic acid. This implies that the surface area is a major factor in achieving high catalytic reactivity of ozone. Nevertheless, using the comparison method whereby the effect of surface area is subtracted, we found from Fig. $6 a$ and $6 b$ that IDR/S and the number of surface $\mathrm{OH}$ per unit area (called density of surface $\mathrm{OH}$ ) is not marked enough for $\mathrm{Al}_{2} \mathrm{O}_{3}$ nanostructures with various morphology. In other words, their surface hydroxyl content makes no obvious difference in the unit area. Thus it is suggested that morphology of alumina has very little influence on the alumina-catalyzed ozonation of pyruvic acid.

Impact of crystal phase of $\mathrm{Al}_{2} \mathrm{O}_{3}$ on heterogeneous catalytic ozonation of pyruvic acid: As reported, all phases of $\mathrm{Al}_{2} \mathrm{O}_{3}$ have defects. $\gamma$ - and $\delta-\mathrm{Al}_{2} \mathrm{O}_{3}$ are aluminum deficient, whereas $\theta$ - and $\alpha-\mathrm{Al}_{2} \mathrm{O}_{3}$ are deficient in oxygen atoms ${ }^{31-34}$. 

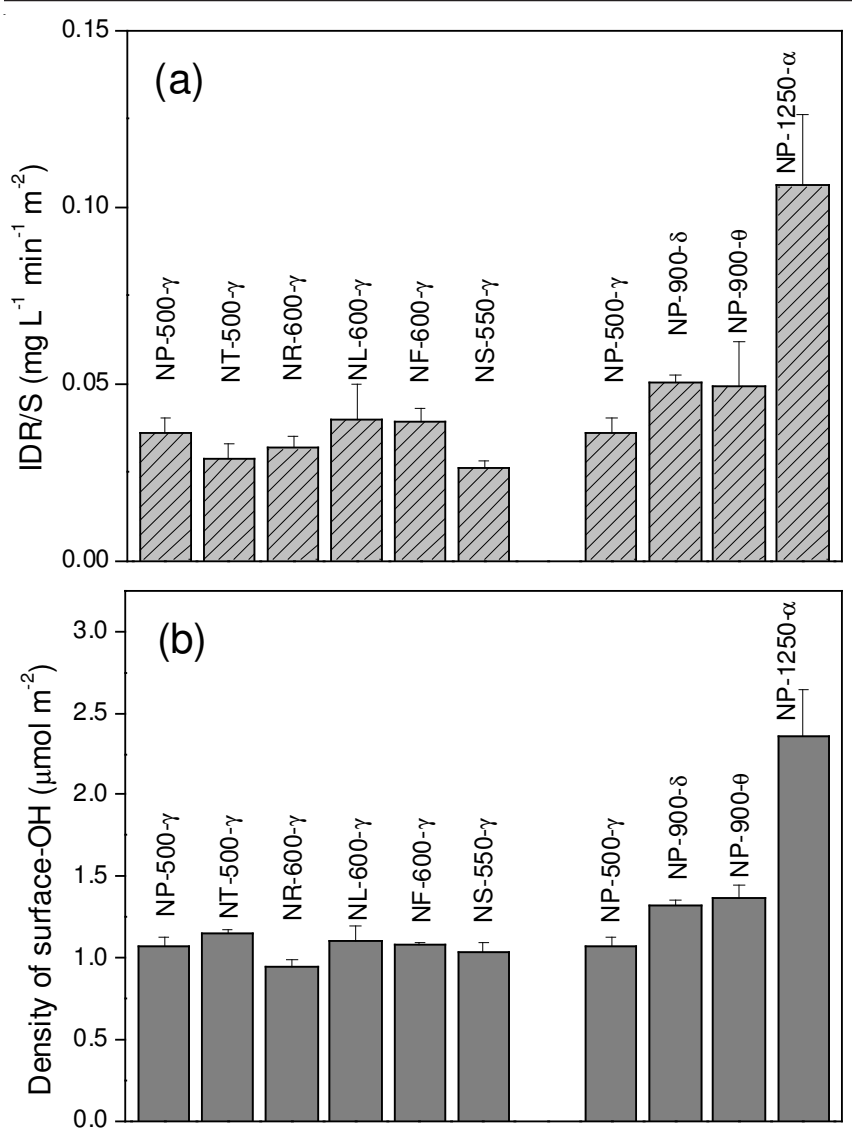

Fig. 6. Comparison of IDR/S (a) and the density of surface $\mathrm{OH}$ groups on catalysts (b) for $\mathrm{Al}_{2} \mathrm{O}_{3}$ with various crystalline phases and morphology

Vacancy defects in the crystalline structures of solid catalysts, both cationic and anionic in the crystalline structures, can act as active reaction centers via the generation of surface $\mathrm{OH}$ groups, thus determining the rate of the heterogeneous ozonation process ${ }^{35}$. To study the effects of phase structures of the alumina nanoparticles on the catalytic activities, rates of ozonation of pyruvic acid with respect to $\gamma-, \delta-, \theta-\mathrm{Al}_{2} \mathrm{O}_{3}$ and $\alpha-\mathrm{Al}_{2} \mathrm{O}_{3}$ were examined. The four samples used in the catalytic activity test were morphologically very similar but presented different surface areas. As shown in Fig. 4b, the $\alpha$ $\mathrm{Al}_{2} \mathrm{O}_{3}$ catalyzed process gave only a $15.4 \%$ decrease in COD after $2 \mathrm{~h}$ of reaction. In comparison, the COD removal is 56.0, 40.3 and $46.7 \%$ for the $\gamma-, \delta$ - and $\theta-\mathrm{Al}_{2} \mathrm{O}_{3}$ nanoparticles, respectively. The initial degradation rate of pyruvic acid degradation followed a very similar trend. In particular, the initial degradation rate of pyruvic acid degradation with NP1250- $\alpha$ was approximately one-seventh smaller than that of the NP-500- $\gamma$. Considering that the BET surface areas can greatly influence the catalytic activity as mentioned above, the BET surface area should be subtracted from initial degradation rate to establish the effect of the nature of the crystalline phase on the catalytic ozonation of pyruvic acid. It is obvious from Fig. 6 and Table- 1 that the IDR/S increased in the following order: $\gamma-\mathrm{Al}_{2} \mathrm{O}_{3}<\delta-\mathrm{Al}_{2} \mathrm{O}_{3} \approx \theta-\mathrm{Al}_{2} \mathrm{O}_{3}<\alpha-\mathrm{Al}_{2} \mathrm{O}_{3}$ and the same trend can be found for the yield in the density of surface $\mathrm{OH}$.

As aforementioned, differences in catalytic activity amongst the various $\mathrm{Al}_{2} \mathrm{O}_{3}$ catalysts depend on the nature of vacancies. In our experiments, using calcination techniques, we converted boehmite to transition $\gamma_{-}, \delta-, \theta-\mathrm{Al}_{2} \mathrm{O}_{3}$ and to finally to $\alpha-\mathrm{Al}_{2} \mathrm{O}_{3}$. It is widely accepted that the high-temperature transition phases are less active than the low temperature ones due to the lower surface area of the former. This effect is brought about by the higher order and larger particle size. Simultaneously, there exists a larger fraction of tetrahedrally coordinated $\mathrm{Al}^{3+}$ ions in the low-temperature transition alumina than in high-temperature transition alumina ${ }^{31}$. However, if we normalized the surface area to account for the relationship between the crystalline phase and surface $\mathrm{OH}$ groups in this work, values of the density of surface $\mathrm{OH}$ groups was found to be decreasing in the order of $\alpha-\mathrm{Al}_{2} \mathrm{O}_{3}>\theta-\mathrm{Al}_{2} \mathrm{O}_{3} \approx$ $\delta-\mathrm{Al}_{2} \mathrm{O}_{3}>\gamma-\mathrm{Al}_{2} \mathrm{O}_{3}$. The $\alpha-\mathrm{Al}_{2} \mathrm{O}_{3}$ appears to be significantly higher than other phases. The following reason can be formulated to explain this sequence. The generation of surface $\mathrm{OH}$ groups in aqueous solution is different from that under ambient conditions. It is well known that hydrated alumina surfaces undergo phase transformations during the hydration process ${ }^{33,36}$. For example, the surface of $\gamma-\mathrm{Al}_{2} \mathrm{O}_{3}$ can hydrate to bayerite with prolonged hydration and a mixture of $\alpha-\mathrm{Al}(\mathrm{OH})_{3}$ and $\gamma-\mathrm{Al}(\mathrm{OH})_{3}$ is produced when the surface of $\alpha-\mathrm{Al}_{2} \mathrm{O}_{3}$ is covered with water ${ }^{37-39}$. In this case, the proportion of singly and doubly coordinated aluminum-oxygen bonding contributes to the amount of surface $\mathrm{OH}$ groups. Therefore, we can deduce that $\mathrm{Al}_{2} \mathrm{O}_{3}$ has various numbers of hydroxyl groups in aqueous solution according to the crystalline phase. $\alpha-\mathrm{Al}_{2} \mathrm{O}_{3}$ possess the highest density of surface $\mathrm{OH}$ groups, followed by $\theta-, \delta$ and finally $\gamma$-. From the above information it is concluded that the crystal phase plays a vital role in the catalytic ozonation process and the $\alpha-\mathrm{Al}_{2} \mathrm{O}_{3}$ phase is more beneficial to the system.

\section{Conclusion}

To summarize, the catalytic activity of $\mathrm{Al}_{2} \mathrm{O}_{3}$ for the oxidation of pyruvic acid with ozone is dominated by surface hydroxyl groups which are dependent mainly upon their specific surface areas and crystal phase, whereas the effect of morphology on the catalytic performance seems to be negligible. A high-activity catalyst requires simultaneously maximizing the surface area and the content of the $\alpha$-form of $\mathrm{Al}_{2} \mathrm{O}_{3}$.

\section{ACKNOWLEDGEMENTS}

This work was supported by the National Natural Science Foundation of China (Grant Nos. 20977086, 21076196 and 21177115), National Basic Research Program of China (Grant No. 2009CB421603) and Zhejiang Provincial Natural Science Foundation of China (Grant Nos. R13B070008 and Y5100310).

\section{REFERENCES}

1. F. Gahr, F. Hermanutz and W. Oppermann, Water Sci. Technol., 30, 255 (1994).

2. B. Legube and N.K.V. Leitner, Catal. Today, 53, 61 (1999).

3. B. Kasprzyk-Hordern, M. Ziólek and J. Nawrocki, Appl. Catal. B: Environ., 46, 639 (2003).

4. F. Qi, B.B. Xu, Z.L. Chen, L.Q. Zhang, P.Y. Zhang and D.Z. Sun, Chem. Eng. J., 165, 490 (2010).

5. C.H. Ni and J.N. Chen, Water Sci. Technol., 43, 213 (2001).

6. C. Cooper and R. Burch, Water Res., 33, 3695 (1999).

7. F.J. Beltrán, F.J. Rivas and R. Montero-de-Espinosa, Appl. Catal. B: Environ., 47, 101 (2004).

8. M. Ernst, F. Lurot and J.C. Schrotter, Appl. Catal. B: Environ., 47, 15 (2004). 
9. P.M. Álvarez, F.J. Beltrán, J.P. Pocostales and F.J. Masa, Appl. Catal. B: Environ., 72, 322 (2007).

10. F. Qi, B.B. Xu, Z.L. Chen, J. Ma, D.Z. Sun and L.Q. Zhang, Sep. Purif. Technol., 66, 405 (2009).

11. S. Song, Z.W. Liu, Z.Q. He, A.L. Zhang and J.M. Chen, Environ. Sci. Technol., 44, 3913 (2010).

12. M. Muruganandham and J.J. Wu, Appl. Catal. B: Environ., 80, 32 (2008).

13. T.L. Kelly, S.P.Y. Che, Y. Yamada, K. Yano and M.O. Wolf, Langmuir, 24, 9809 (2008).

14. Y.M. Dong, H.X. Yang, K. He, S.Q. Song and A.M. Zhang, Appl. Catal. B: Environ., 85, 155 (2009).

15. S.H. Cai, S.N. Rashkeev, S.T. Pantelides and K. Sohlberg, Phys. Rev. B, 67, 224104 (2003)

16. C.L. Lu, J.G. Lv, L. Xu, X.F. Guo, W.H. Hou, Y. Hu and H. Huang, Nanotechnology, 20, 215604 (2009).

17. Y. Liu, D. Ma, X.W. Han, X.H. Bao, W. Frandsen, D. Wang and D.S. Su, Mater. Lett., 62, 1297(2008).

18. A. Takagaki, M. Sugisawa, D.L. Lu, J.N. Kondo, M. Hara, K. Domen and S. Hayashi, J. Am. Chem. Soc., 125, 5479 (2003).

19. Y. Zhu, H.W. Hou, G.L. Tang and Q.Y Hu, Eur. J. Inorg. Chem., 6, 872 (2010).

20. Z.W. Liu, K.W. Jun, H.S. Roh, S.E. Park and T.Y. Song, Korean J. Chem. Eng., 19, 735 (2002).

21. Z.W. Liu, H.S. Roh, K.W. Jun, S.E. Park and T.Y. Song, Korean J. Chem. Eng., 19, 742 (2002).

22. B.S. Caglayan, A.K. Avci, Z.I. Onsan and A.E. Aksoylu, Appl. Catal. A, 280, 181 (2005).
23. C.D. Jones and A.R. Barron, Mater. Chem. Phys., 104, 460 (2007)

24. X.Y. Chen, H.S. Huh and S.W. Lee, Nanotechnology, 18, 285608 (2007).

25. X.Y. Chen, Z.H. Zhang, X.L. Li and S.W. Lee, Solid State Commun., 145, 368 (2008).

26. W.Q. Cai, J.G. Yu and M. Jaroniec, J. Mater. Chem., 20, 4587 (2010).

27. K. Rakness, G. Gordon, B. Langlais, W. Masschelein, N. Matsumoto, Y. Richard, C.M. Robson and I. Somiya, Ozone Sci. Eng., 18, 209 (1996).

28. P.C. Hidber, T.J. Graule and L.J. Gauckler, J. Eur. Ceram. Soc., 17, 239 (1997).

29. E. Laiti, L.O. Ohman, J. Nordin and S. Sjoberg, J. Colloid Interf. Sci., 175, 230 (1995).

30. A.D. Megias, E. Tervoort, C. Cattin and L.J. Gauckler, J. Colloid Interf. Sci., 353, 512 (2011)

31. C. Morterra and G. Magnacca, Catal. Today, 27, 497 (1996).

32. I. Levin and D. Brandon, J. Am. Ceram. Soc., 81, 1995 (1998).

33. J.A. Wang, X. Bokhimi, A. Morales, O. Novaro, T. López and R. Gómez, J. Phys. Chem. B, 103, 299 (1999).

34. I.A. Weinstein and E.A. Popko, J. Luminescence, 122, 377 (2007).

35. X.F. Yang, Z.X. Sun, D.S. Wang and W. Forsling, J. Colloid Interf. Sci., 308, 395 (2007).

36. B. Kasprzyk-Hordern, Adv. Colloid. Interf., 110, 19 (2004).

37. C. Dyer, P.J. Hendra, W. Forsling and M. Ranheimer, Spectrochim. Acta A, 49, 691 (1993).

38. E. Laiti, P. Persson and L.O. Ohman, Langmuir, 14, 825 (1998).

39. G. Lèfevre, M. Duc, P. Lepeut, R. Caplain and M. Fédoroff, Langmuir, 18, 7530 (2002). 